\title{
Neprilysin inhibitors as a new approach in the treatment of right heart failure in the course of chronic obstructive pulmonary disease. Response to the letter of Siniorakis et al.
}

\author{
The authors declare no finacial disclosure
}

Neprilysin (NEP) inhibition has become an important issue in cardiology and pulmonology. Among others, it is reflected by the constantly growing number of articles discussing this topic found on PubMed. However, it is worth exploring the multidimensional role of Neprilysin, as well as its inhibition in many diseases. Our article also tackles the issue of unexpected complications that may develop in patients with chronic obstructive pulmonary disease (COPD) due to NEP inhibition.

The problem with assessing safety and adverse reactions of neprilysin inhibitors results from the enzyme's multifunctional nature. Neutral endopeptidase 24.11 is responsible for metabolizing numerous substances which often act in opposition to each other. Therefore, when planning studies in this area it must be remembered that NEP is not only associated with metabolism of natriuretic peptides but is also related to numerous pleiotropic mechanisms.

Right ventricular failure is one of the most serious complications of COPD which significantly deteriorates prognosis in this disease [1]. Therefore, due to the confirmed efficacy in heart failure therapy (PARADIGM-HF), administration of angiotensin receptor-neprilysin inhibitors (ARNI) in this group of patients may bring considerable therapeutic benefits that exceed possible adverse reactions. The PARADIGM-HF study that involved a group of more than eight thousand subjects proved the advantages of ARNI therapy in patients with HFrEF as compared to ACEI. In the group of patients receiving ARNI the observed mortality caused by cardiovascular problems, as well as the number of first hospitalizations due to $\mathrm{HF}$, were lower than in the case of enalapril therapy $(21.8 \%$ vs $26.5 \%)[2,3]$.

The efficacy of ARNI therapy is not limited to HFrEF only. The Paramount study focused on HfpEF patients. Entresto decreased the level of $\mathrm{N}$-terminal pro-B-type natriuretic peptide (NT-proBNP) as compared to valsartan, however, this difference was not statistically significant after 36 weeks of the study. Nevertheless, it is worth remembering that Entresto decreased the left atrial volume and size to a greater extent $[2,3]$.

We are still waiting for the results of the PARAGON-HF trial which is to verify the efficacy of HfpEF therapy with the use of sacubitril/ /valsartan in over four thousand patients under planned monitoring for 57 weeks [2].

The potential adverse reactions involving the respiratory system include bronchoconstriction, which is among others related to inhibition of metabolism of $\mathrm{P}$ substance, neurokinin $\mathrm{A}$ and bradykinin [3].

Apart from its vasodilatory properties, bradykinin at high levels induces airway smooth muscle contraction. It is also a pro-inflammatory

\footnotetext{
Address for correspondence: Michal Panek, Department of Internal Medicine, Asthma and Allergy, Medical University of Lodz, Poland, Kopcińskiego 22, 90-153 Łódź, michalmp@poczta.onet.pl 
mediator and may cause angioedema [4]. Therefore, there is a reasonable concern that neprilysin inhibitors may increase the level of bradykinin in the lungs and exacerbate symptoms in patients suffering from asthma or COPD. On the other hand, neutral endopeptidase 24.11 causes an increase in the level of natriuretic peptides having bronchodilatory and immunosuppressive properties, which could lessen the effect of bradykinin action [5]. Moreover, there are studies suggesting that natriuretic peptides, as natural antagonists of $\mathrm{B}_{2} \mathrm{R}$ signaling pathway may decrease the harmful consequences of BK activity [6]. De Gouw et al. [7] conducted a study in which he assessed exercise-induced bronchoconstriction triggered in asthmatic patients who were administered NEP/ thiorphan inhibitor prior to an exercise stress test. In these patients bronchoconstriction was not more aggravated than in a placebo group, and during the convalescence period it was even lower.

In the patients treated with the medicinal product Entresto (sacubitril/valsartan), an occurrence of angioedema was reported. The PARADIGM-HF study showed that the number of confirmed angioedema cases for sacubitril/ /valsartan as compared to enalapril during a double-blind trial was $19(0.45 \%)$ vs $10(0.24 \%)$ (the relative risk was 1.9 [95\%CI $0.8-4.5$ ], thus the risk of occurrence of this adverse reaction was assessed as low. It is worth mentioning that no increased risk of angioedema was observed in current smokers administered sacubitril/valsartan or enalapril [8].

Another potentially harmful effect brought by neprilysin inhibition is suppression of Endotelin-1 metabolism. ET-1 is a peptide with strong vasoconstrictive properties which exerts a long-term effect on vascular smooth muscle cell (VSMC) proliferation and their phenotype [9]. Through $\mathrm{ET}_{\mathrm{A}}$ and $\mathrm{ET}_{\mathrm{B}}$ receptors, ET-1 stimulates pulmonary fibroblast proliferation, which makes it an important compound that plays its role in pulmonary vascular remodeling and pathology of pulmonary hypertension [10]. On the other hand, neprilysin inhibition leads to an increase in natriuretic peptides which suppress various growth factor-stimulated VSMC migration and proliferation, hinder fibroblast proliferation and extracellular matrix production, in particular CNP. In addition, CNP suppresses ET-1 secretion from endothelial cells [11]. Kohno et al. [12] showed that ANP and BNP suppress secretion of endothelin-1 following Ang II stimulation, probably through a cGMP-dependent process.
We also managed to find scientific evidence proving that NEP inhibition reduces the right ventricular hypertrophy which is a serious complication of pulmonary hypertension. Klinger et al. [13] showed that neutral endopeptidase 24.11 inhibition attenuates development of hypoxic pulmonary hypertension in rats. The study revealed a lower systolic pressure of the right ventricle, lower right ventricle weight-to-left ventricle + septum weight ratio and a decreased muscularization and percent medial wall thickness of the peripheral pulmonary arteries than in rats treated with vehicle only. Another study on rats with hypoxic pulmonary hypertension showed that a short-term NEP suppression causes a regression of pulmonary vascular remodeling and may be a useful therapeutic strategy in pulmonary hypertension treatment [14].

However, we may also find studies which show a reduced NEP expression in the lungs of patients with COPD and pulmonary vessel remodeling, and strategies aimed at increasing the level/expression of NEP may bring therapeutic benefits related to prevention and treatment of pulmonary hypertension [15].

As we mentioned in our article, the role of neprilysin as a factor responsible for amyloid-beta degradation is well known. However, NEP is not the only protein responsible for amyloid beta degradation. This function is also fulfilled by cathepsin $G$ and insulin degrading enzyme [16, 17]. Moreover, Maarouf CL and colleagues suggest it is the liver that plays the key role in amyloid-beta metabolism. In that study NEP expression in the human liver homogenates was evaluated with the use of western blot method and it was shown that there were no significant differences in the protein expression in healthy subjects as compared to patients with Alzheimer's disease [16]. It is also worth mentioning that according to the most recent findings [18, 19] heart failure may be a risk factor in Alzheimer's disease as a result of a reduced cerebral blood flow and neurohormonal activation, which leads to the cardiovascular system malfunction. There is no hard research or clinical data on potential exacerbation or an increased risk of Alzheimer's disease development. It is also worth remembering that Food and Drug Administration (FDA) required that NOVARTIS company conducted a multicenter randomized, double-blind, active-controlled trial to evaluate the influence of sacubitril/valsartan on the cognitive functions in patients with chronic HFpEF. It analyzed the cognitive functions based on neurocognitive tests and positron emission tomography. The study is expected to be completed in 2022 [3]. 
It must be remembered that many articles on potential negative effects of NEP inhibition in patients with COPD are based on animal models, which number was not large enough, therefore, there is still no strong scientific evidence in this field. The fact that information on neprilysin inhibition in potential pulmonological patients presented in research publications is so ambiguous suggests that there is a strong need to develop studies in this respect.

Our team is going to apply for a grant to conduct a study on the influence of ARNI therapy on exacerbation of COPD in patients with RHF at the stable stage of the disease. Considering the studies that indicate the ambiguous impact of NEP inhibition in these patients, we will monitor the subjects' levels of PDGF, PDGFR, ET-1, FGF-2, BNP, NT-proBNP and NEP. We will also try to identify characteristic features of pulmonary hypertension in ECG tests.

\section{Conflict of interest}

The authors declared no conflict of interest.

\section{References:}

1. Flessas N, Alexanian I, Parissis J, et al. Plasma activity of B-type natriuretic peptide in patients with biventricular heart failure versus those with right heart failure due to chronic obstructive pulmonary disease. J Cardiovasc Med (Hagerstown). 2014; 15(6): 476-480, doi: 10.2459/JCM.0000000000000007, indexed in Pubmed: 24983267.

2. Ambrosy AP, Mentz RJ, Fiuzat M, et al. The role of angiotensin receptor-neprilysin inhibitors in cardiovascular disease-existing evidence, knowledge gaps, and future directions. Eur J Heart Fail. 2018; 20(6): 963-972, doi: 10.1002/ejhf.1159, indexed in Pubmed: 29464817.

3. Campbell DJ. Long-term neprilysin inhibition - implications for ARNIs. Nat Rev Cardiol. 2017; 14(3): 171-186, doi: 10.1038/ nrcardio.2016.200, indexed in Pubmed: 27974807.

4. Golias Ch, Charalabopoulos A, Stagikas D, et al. The kinin system--bradykinin: biological effects and clinical implications. Multiple role of the kinin system--bradykinin. Hippokratia. 2007; 11(3): 124-128, indexed in Pubmed: 19582206.

5. Liczek M, Panek I, Damiański P, et al. Neprilysin inhibitors as a new approach in the treatment of right heart failure in the course of chronic obstructive pulmonary disease. Adv Respir Med. 2018; 86: 183-191, doi: 10.5603/ARM.a2018.0028, indexed in Pubmed: 30110121.
6. Dobrivojević M, Sinđić A, Edemir B, et al. Interaction between bradykinin and natriuretic peptides via RGS protein activation in HEK-293 cells. Am J Physiol Cell Physiol. 2012; 303(12): C1260-C1268, doi: 10.1152/ajpcell.00033.2012, indexed in Pubmed: 23054060.

7. de Gouw H, Diamant E, Kuijpers E. Role of neutral endopeptidase in exercise-induced bronchoconstriction in asthmatic subjects. J Appl Physiol (1985) 1996; 81(2):673-8. Shi V, Senni M, Streefkerk H, et al. Angioedema in heart failure patients treated with sacubitril/valsartan (LCZ696) or enalapril in the PARADIGM-HF study. Int J Cardiol. 2018; 264: 118-123, doi: 10.1016/j.ijcard.2018.03.121, indexed in Pubmed: 29776559.

8. D’Elia E, Iacovoni A, Vaduganathan M, et al. Neprilysin inhibition in heart failure: mechanisms and substrates beyond modulating natriuretic peptides. Eur J Heart Fail. 2017; 19(6): 710-717, doi: 10.1002/ejhf.799, indexed in Pubmed: 28326642.

9. Shi V, Senni M, Streefkerk H, et al. Angioedema in heart failure patients treated with sacubitril/valsartan (LCZ696) or enalapril in the PARADIGM-HF study. Int J Cardiol. 2018; 264: 118-23.

10. Jeffery TK, Wanstall JC. Pulmonary vascular remodeling: a target for therapeutic intervention in pulmonary hypertension. Pharmacol Ther. 2001; 92(1): 1-20, indexed in Pubmed: 11750034.

11. Minamino N, Nishikimi T. Natriuretic Peptides. Handbook of Biologically Active Peptides. 2013: 1415-1422, doi: 10.1016/ b978-0-12-385095-9.00192-5.

12. Kohno M, Yokokawa K, Horio T, et al. Atrial and brain natriuretic peptides inhibit the endothelin-1 secretory response to angiotensin II in porcine aorta. Circ Res. 1992; 70(2): 241-247, indexed in Pubmed: 1310444.

13. Klinger JR, Petit RD, Warburton RR, et al. Neutral endopeptidase inhibition attenuates development of hypoxic pulmonary hypertension in rats. J Appl Physiol (1985). 1993; 75(4): 16151623, doi: 10.1152/jappl.1993.75.4.1615, indexed in Pubmed: 8282611.

14. Thompson JS, Sheedy W, Morice AH. Neutral endopeptidase (NEP) inhibition in rats with established pulmonary hypertension secondary to chronic hypoxia. British Journal of Pharmacology. 2012; 113(4): 1121-1126, doi: 10.1111/j.14765381.1994.tb17112.x.

15. Karoor V, Oka M, Walchak SJ, et al. Neprilysin regulates pulmonary artery smooth muscle cell phenotype through a platelet-derived growth factor receptor-dependent mechanism. Hypertension. 2013; 61(4): 921-930, doi: 10.1161/HYPERTENSIONAHA.111.199588, indexed in Pubmed: 23381789.

16. Maarouf CL, Walker JE, Sue LI, et al. Impaired hepatic amyloid-beta degradation in Alzheimer's disease. PLoS One. 2018; 13(9): e0203659, doi: 10.1371/journal.pone.0203659, indexed in Pubmed: 30192871.

17. Saido T, Leissring MA. Proteolytic degradation of amyloid $\beta$-protein. Cold Spring Harb Perspect Med. 2012; 2(6): a006379, doi: 10.1101/cshperspect.a006379, indexed in Pubmed: 22675659.

18. Patel N, Gluck J. Is Entresto good for the brain? World J Cardiol. 2017; 9(7): 594-599, doi: 10.4330/wjc.v9.i7.594, indexed in Pubmed: 28824789.

19. Cermakova P, Eriksdotter M, Lund LH, et al. Heart failure and Alzheimer's disease. J Intern Med. 2015; 277(4): 406-425, doi: 10.1111/joim.12287, indexed in Pubmed: 25041352. 